\title{
Zoledronic acid sensitizes breast cancer cells to fulvestrant via ERK/HIF-1 pathway inhibition in vivo
}

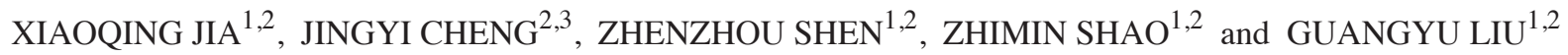 \\ ${ }^{1}$ Department of Breast Surgery, Key Laboratory of Breast Cancer in Shanghai, Fudan University Shanghai Cancer Center; \\ ${ }^{2}$ Department of Oncology, Shanghai Medical College, Fudan University; ${ }^{3}$ Department of Nuclear Medicine, \\ Fudan University Shanghai Cancer Center, Shanghai 200032, P.R. China
}

Received November 7, 2016; Accepted November 28, 2017

DOI: $10.3892 / \mathrm{mmr} .2018 .8514$

\begin{abstract}
Previous studies have reported that hypoxia-inducible factor (HIF)-1 $\alpha$ confers endocrine resistance and that zoledronic acid (ZOL) decreases HIF-1 $\alpha$ expression in estrogen receptor-positive breast cancer. The present study investigated the effect of the combination treatment with $\mathrm{ZOL}$ and fulvestrant and its possible mechanism for HIF-1 $\alpha$ inhibition in vitro and in vivo. First, cell proliferation, clonogenic ability and HIF-1 $\alpha$ expression by western blotting were determined in MCF-7 breast cancer cells stably expressing HIF-1 $\alpha$ in vitro. Next, a mouse xenograft model was established with the HIF-1 $\alpha$-overexpressing MCF-7 breast cancer cells, and treated with PBS, fulvestrant, ZOL or fulvestrant plus ZOL. Tumor volumes were compared and animal $\left[{ }^{18} \mathrm{~F}\right]$-fluoromisonidazole (FMISO) positron emission tomography-computer tomography (PET-CT) was used to detect the hypoxic status of the xenograft tumors. Protein expression levels of HIF-1 $\alpha$ in the xenograft tumors were detected by immunohistochemistry and western blotting. The results demonstrated that the HIF-1 $\alpha$-overexpressing xenograft tumors grew faster and larger compared with control tumors. The animal $\left[{ }^{18} \mathrm{~F}\right]$-FMISO PET-CT also confirmed these results. $\left[{ }^{18} \mathrm{~F}\right]$-FMISO uptake was significantly higher in HIF-1 $\alpha$-overexpressing xenograft tumors compared with control tumors. In addition, the combination treatment with ZOL and fulvestrant acted synergistically in the mouse xenograft model in vivo to significantly reduce tumor burden. Similarly, combination of ZOL and fulvestrant significantly reduced tumor cell growth in vitro. ZOL alone did not inhibit the tumor growth of MCF-7 cells stably expressing HIF-1 $\alpha$. Furthermore, ZOL significantly inhibited extracellular
\end{abstract}

Correspondence to: Dr Guangyu Liu, Department of Breast Surgery, Key Laboratory of Breast Cancer in Shanghai, Fudan University Shanghai Cancer Center, 270 Dong-An Road, Shanghai 200032, P.R. China

E-mail: liugy688@163.com

Key words: zoledronic acid, hypoxia-inducible factor-1 $\alpha$, fulvestrant, breast cancer signal-regulated kinase (ERK) 1/2 phosphorylation, while phosphoinositide 3-kinase/AKT signaling was not affected. In conclusion, the present study demonstrated that $\mathrm{ZOL}$ significantly increased the sensitivity of breast cancer cells to fulvestrant through inhibition of the ERK/HIF-1 $\alpha$ pathway.

\section{Introduction}

Breast cancer is ranked the first cause of cancer-related deaths in women worldwide (1). As in most other countries, breast cancer is now the most common cancer in Chinese women $(2,3)$. Estrogen receptor (ER)-positive breast cancer accounts for $70-80 \%$ of all breast cancers, for which endocrine therapy is the most effective treatment $(4,5)$. Fulvestrant is a selective estrogen receptor downregulator, which has been approved by FDA for the treatment of advanced ER-positive breast cancer (6,7). However, fulvestrant resistance is unavoidable during the treatment period.

Bisphosphonates (BPs) have been widely and successfully used for the treatment of bone metastases in breast cancer patients (8). Zoledronic acid (ZOL) is a third-generation BP, which has the most potent inhibitory effect on osteoclast-mediated bone resorption among currently available BPs $(9,10)$. In addition to its potent anti-osteoclast effects, preclinical studies have reported that $\mathrm{ZOL}$ induces apoptosis in breast cancer cells $(11,12)$. It has also been demonstrated that ZOL inhibits cancer cell invasion $(13,14)$ and angiogenesis $(15,16)$. However, the effects of $\mathrm{ZOL}$ on endocrine resistance of breast cancer have not been extensively investigated.

Previous studies have shown that hypoxia may lead to endocrine resistance in ER-positive breast cancer patients (17). Hypoxia inducible factor (HIF)-1 $\alpha$ expression is significantly increased in residual tumors following endocrine therapy (18). The MCF-7 breast cancer cell line stably expressing HIF-1 $\alpha$ has been reported to be insensitive to fulvestrant in vivo (18). ZOL inhibits HIF-1 $\alpha$ expression in the neoadjuvant endocrine therapy set (18). In the present study, the effect of ZOL on fulvestrant response and the underlying mechanisms were investigated in a mouse model and in vitro.

\section{Materials and methods}

Chemicals and antibodies. Fulvestrant and ZOL were kindly provided by AstraZeneca PLC (Cambridge UK) and Novartis 
Pharma AG (Basel Switzerland), respectively. Cobalt chloride $\left(\mathrm{CoCl}_{2}\right)$ and epidermal growth factor (EGF) were purchased from Sigma-Aldrich (Merck KGaA, Darmstadt, Germany). Mouse monoclonal antibody against HIF-1 $\alpha$ was purchased from BD Biosciences (cat no. 610958; 1:1,000; Franklin Lakes, NJ, USA). Rabbit polyclonal antibodies against phosphoinositide 3-kinase (PI3K; cat no. 4255; 1:1,000), AKT serine/threonine kinase 1 (AKT; cat no. 9272; 1:1,000), phosphorylated (p-) AKT (cat no. 4060; 1:1,000), extracellular signal-regulated kinase (ERK) $1 / 2$ (cat no. 4695; 1:2,000), p-ERK1/2 (cat no. 4376; 1:2,000) were purchased from Cell Signaling Technology, Inc. (Danvers, MA, USA). Antibodies against $\beta$-actin (cat no. 60008-1-Ig; 1:2,000) and GAPDH (cat no. 60004-1-Ig; 1:2,000) were from ProteinTech Group, Inc. (Chicago, IL, USA).

Generation of HIF-la stably expressing cells. Generation of the HIF-1 $\alpha$ stably expressing cell lines has been reported previously (18). Full-length cDNA of HIF-1 $\alpha$ was amplified by polymerase chain reaction (PCR). The lentiviral expression and control vectors were packed into HEK 293T cells to generate the corresponding lentiviruses. Transfections were performed using olyethylenimine. MCF-7 cells infected with HIF-1 $\alpha$ or vector control lentiviruses (designated MCF-7/HIF-1 $\alpha$ or MCF-7/vector, respectively) were selected and maintained in the same medium containing $2 \mu \mathrm{g} / \mathrm{ml}$ puromycin (Sigma-Aldrich; Merck KGaA). Non-infected cells were completely eradicated by puromycin selection for $72 \mathrm{~h}$. The surviving lentivirus-infected cells were confirmed to successfully express HIF-1 $\alpha$ by western blot analysis.

Cell culture and treatments. All cell lines were obtained from the American Type Culture Collection (Manassas, VA, USA) and maintained in RPMI 1640 (Shanghai Basalmedia Technologies Co., Ltd., Shanghai, China) supplemented with $10 \%$ fetal bovine serum (Biological Industries, Cromwell, CT, USA) and $5 \%$ penicillin/streptomycin at $37^{\circ} \mathrm{C}$ under $5 \% \mathrm{CO}_{2}$. Cells were treated with drugs at the indicated final concentrations. To establish hypoxic conditions, cells were treated with $200 \mu$ mol cobalt chloride $\left(\mathrm{CoCl}_{2}\right)$ for $24 \mathrm{~h}$, with or without the addition of $100 \mu \mathrm{mol} \mathrm{ZOL}$ for $18 \mathrm{~h}$ after $6 \mathrm{~h}$ of $\mathrm{CoCl}_{2}$ treatment.

Animal model. Xenograft tumors in mice were generated with MCF-7 cells, as previously reported (18). Briefly, a $0.72 \mathrm{mg}$ 90-day-release $17 \beta$-estradiol pellet (Innovative Research of America, Sarasota, FL, USA) was implanted subcutaneously one week prior to injection. MCF-7/vector and MCF-7/HIF-1 $\alpha$ cells $\left(1 \times 10^{7}\right)$ were resuspended in PBS, mixed with Matrigel (1:1; BD Biosciences) and injected subcutaneously into the right flank of each mouse in a final volume of $200 \mu \mathrm{l}$. Treatment began when tumors reached an average size of 150-200 $\mathrm{mm}^{3}$. The animals were randomly allocated to four groups: Control (PBS; $0.1 \mathrm{ml}$ administered subcutaneously once per week), fulvestrant $(5 \mathrm{mg} / \mathrm{kg}$ administered subcutaneously once per week), ZOL (120 $\mu \mathrm{g} / \mathrm{kg}$ administered subcutaneously twice per week) or fulvestrant plus ZOL). Tumor xenografts were measured with calipers twice a week, and tumor volume was determined using the formula: $\mathrm{v}=\frac{\text { length }}{2} \times$ width $h^{2}$. Tumors were harvested following 4 weeks of treatment. Half of each tumor was flash-frozen in liquid nitrogen, and the other half was fixed in $10 \%$ formalin for $24 \mathrm{~h}$ prior to paraffin-embedding.
All of the animal experiments were approved by the Ethical Committee of Fudan University Shanghai Cancer Hospital (Shanghai, China).

Animal $\left[{ }^{18} \mathrm{~F}\right]$-fluoromisonidazole (FMISO) static positron emission tomography-computer tomography (PET/CT) scan. $\left[{ }^{18} \mathrm{~F}\right]$-FMISO PET/CT scans were acquired before the mice were euthanized. $\left[{ }^{18} \mathrm{~F}\right]$-FMISO is the most widely used nitroimidazole derivative in clinical PET/CT. Because $\left[{ }^{18} \mathrm{~F}\right]-\mathrm{FMISO}$ has affinity only for hypoxic cells with functionally active nitroreductase enzymes, $\left[{ }^{18} \mathrm{~F}\right]$-FMISO accumulates in activated hypoxic cells but not in necrotic cells.

All mice were injected intravenously with $500 \mu \mathrm{ci}$ of $\left[{ }^{18} \mathrm{~F}\right]-\mathrm{FMISO}$. At $4 \mathrm{~h}$ following injection, static emission scans were obtained. The data acquisition time was 5 min per table position. $\left[{ }^{18} \mathrm{~F}\right]$-FMISO PET/CT images at $4 \mathrm{~h}$ were noted as SUV4 hT. In addition, six $0.5 \times 0.5 \times 0.5 \mathrm{~cm}$ small spheres (background) were located at the triceps brachii muscles, the scapula muscles, and the latissimus dorsi muscles both in the homonymy and in the opposite side. The mean value of the six background volume of interest (VOI) peaks was noted as SUV4 hB. The tumor-to-background ratio (TBR) was calculated as follows: TBR $4 \mathrm{~h}=\frac{S U V 4 h T}{S U V 4 h B}$.

Immunohistochemical (IHC) staining. The paraffin-embedded mouse tumor tissue sections $(5 \mu \mathrm{m})$ were dehydrated and subjected to peroxidase blocking with $5 \%$ goat serum for $1 \mathrm{~h}$ at room temperature. HIF- $1 \alpha$ primary antibody $(1: 100)$ was added and incubated at $4^{\circ} \mathrm{C}$ overnight. Immunoreactivity was detected by using the EnVision+System (DAKO; Agilent Technologies, Inc., Santa Clara, CA, USA) with diaminobenzidine chromogen, according to the manufacturer's protocol. The stained slides were observed with microscopy, and images were acquired with Adobe Photoshop CS5 (Adobe Systems, Inc., San Jose, CA, USA). HIF-1 $\alpha$ levels were assessed within the entire tumor section with a semi-quantitative scale that combined proportional expression $(0$, no expression; $1,<10 \%$; $2,10-50 \% ; 3,50-80 \%$; or $4,>80 \%$ of cells with positive nuclear staining) and staining intensity ( 0 , none; 1 , weak; 2 , intermediate; or 3 , strong) to obtain a total IHC score ranging from 0 to 7 .

Cell proliferation and cell clonogenic assays. Cell proliferation assays and cell clonogenic assays were performed as previously described (18). For cell proliferation assays, cells were seeded in 96-well plates $(3,000$ cells/well) in triplicate and cultured overnight. Then cells were treated with PBS, ZOL, fuvestrant, or ZOL plus fuvestrant for $48 \mathrm{~h}$, followed by Cell Counting Kit-8 assay (Dojindo Molecular Technologies, Inc., Kumamoto, Japan), according to the manufacturer's instructions. For clonogenic assays, cells were seeded in 6 -well plates (300 cells/well) in triplicate and cultured overnight. Then the cells were treated with PBS, ZOL, fuvestrant, or ZOL plus fuvestrant for 14 days. Representative results of three independent experiments with similar trends are presented.

Western blotting. Cells were washed twice with cold PBS and centrifuged at $500 \mathrm{x}$ g for $3 \mathrm{~min}$. The cell pellet was suspended in $80 \mu 1$ lysis buffer (Thermo Fisher Scientific, Inc., Waltham, 
A

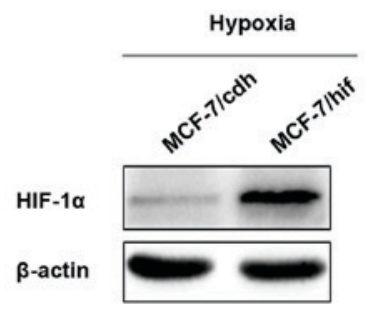

B

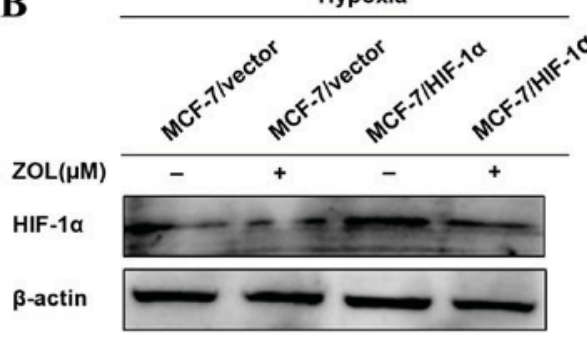

C
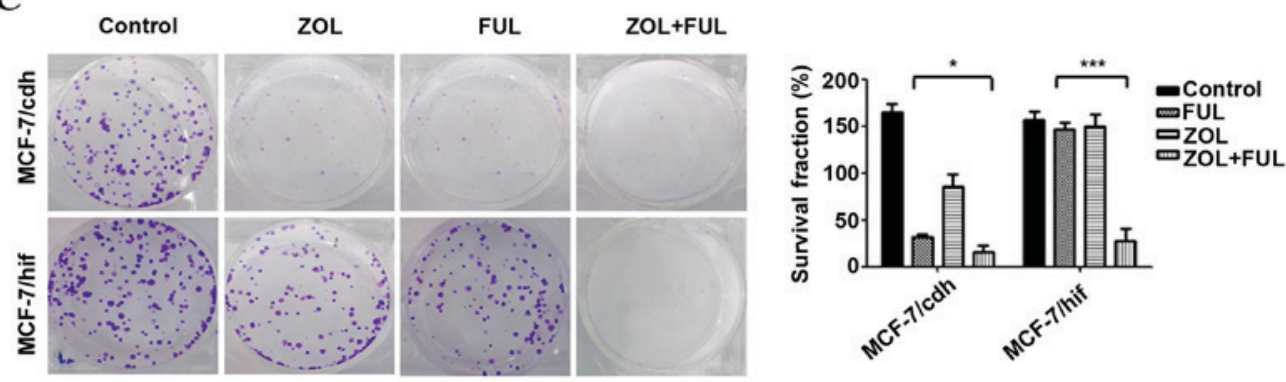

D
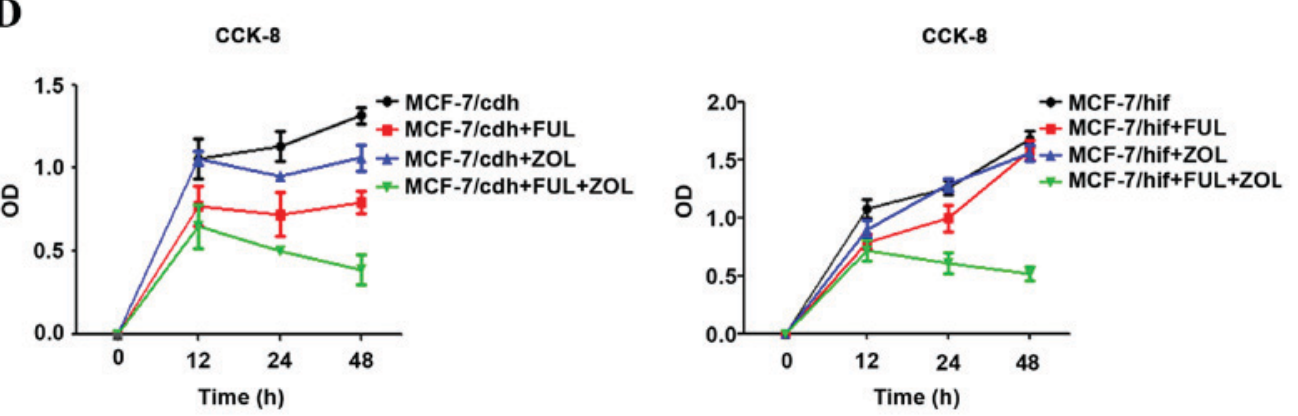

Figure 1.ZOL exerts antitumor activity in HIF-1 $\alpha$-overexpressing breast cancer cells and synergizes with fulvestrant in vitro. (A) Western blot analysis of the control MCF-7/vector and MCF-7/HIF-1 $\alpha$ cells, demonstrating that HIF-1 $\alpha$ overexpression was successfully established. (B) MCF-7/HIF-1 $\alpha$ and MCF-7/vector cells were pre-treated with $200 \mu \mathrm{mol} \mathrm{CoCl}$ for $6 \mathrm{~h}$ followed by treated with $\mathrm{CoCl}_{2}$ and $100 \mu \mathrm{mol} \mathrm{ZOL} \mathrm{for} 18 \mathrm{~h}$ and western blot analysis was used to detect $\mathrm{HIF}-1 \alpha$ expression. (C) Growth of MCF-7/HIF-1 $\alpha$ and MCF-7/vector cells treated with $100 \mu \mathrm{mol} \mathrm{ZOL}$ and/or $0.1 \mathrm{nmol} / 1$ fulvestrant for two weeks, as determined by colony formation assay. Control is untreated cells. (D) Viability of MCF-7/ HIF-1 $\alpha$ and MCF-7/vector cells treated with $100 \mu \mathrm{mol} \mathrm{ZOL} \mathrm{and/or} \mathrm{0.1} \mathrm{nmol/1} \mathrm{fulvestrant} \mathrm{for} \mathrm{0,} \mathrm{12,} \mathrm{24,} \mathrm{48} \mathrm{h,}$ as determined by Cell Counting Kit- 8 assay. ${ }^{*} \mathrm{P}<0.05$ and ${ }^{* * *} \mathrm{P}<0.001$ vs. untreated control. ZOL, zoledronic acid; HIF, hypoxia-inducible factor; FUL, fulvestrant; OD, optical density.

MA, USA). The suspension was incubated on ice for $40 \mathrm{~min}$ and centrifuged for $10 \mathrm{~min}$ at $16,000 \mathrm{x}$ g. Protein concentration was determined with a bicinchoninic acid protein assay kit (Beyotime Institute of Biotechnology, Haimen, China). Cell lysates $(50 \mu \mathrm{g})$ were resolved by $10 \%$ SDS-PAGE, and electrophoretically transferred to nitrocellulose membranes (EMD Millipore, Billerica, MA, USA), Following blocking with 5\% BSA for $1 \mathrm{~h}$ at room temperature, membranes were hybridized overnight at $4^{\circ} \mathrm{C}$ with primary antibodies specific for the detection of each protein and GAPDH (used as a loading control). Horseradish peroxidase-conjugated secondary antibodies (cat nos. 715-035-150 and 415-035-166; Jackson ImmunoResearch Laboratories, Inc., West Grove, PA, USA) were used at 1:5,000 dilution in TBS-Tween 20 solution for $1 \mathrm{~h}$ at room temperature. Protein-antibody complexes were detected by chemiluminescence with the Super Signal West Dura Extended Duration Substrate (EMD Millipore), and images were captured with an ImageQuant LAS 4000 biomolecular imager (GE Healthcare Life Sciences, Little Chalfont, UK). The experiments were repeated at least three times.
Statistical analysis. Each experiment was repeated independently three times. Statistical significance of differences between two groups were analyzed with Student's t-test, and among multiple groups with one-way analysis of variance followed by the Student-Newman-Keuls test for post-hoc analysis. All analyses were performed with SPSS 18.0 (SPSS, Inc., Chicago, IL, USA). $\mathrm{P}<0.05$ was considered to indicate a statistically significant difference.

\section{Results}

ZOL exerts antitumor activity on HIF-1 $\alpha$-overexpressing breast cancer cells and synergizes with fulvestrant in vitro. Previous studies have reported that HIF-1 $\alpha$ is overexpressed following neoadjuvant endocrine therapy and breast cancer cells overexpressing HIF-1 $\alpha$ are resistant to fulvestrant, which suggests that HIF-1 $\alpha$ may confer endocrine resistance (18). To identify the effect of ZOL in fulvestrant treatment, HIF-1 $\alpha$-overexpressing MCF-7 breast cancer cells were used (termed MCF-7/HIF-1 $\alpha$; Fig. 1A). It was observed that HIF-1 $\alpha$ 
A

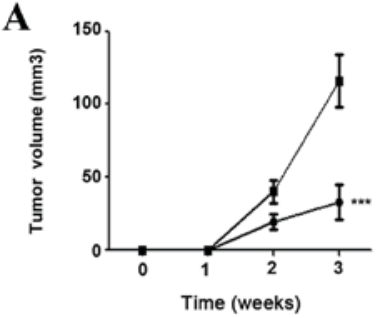

C

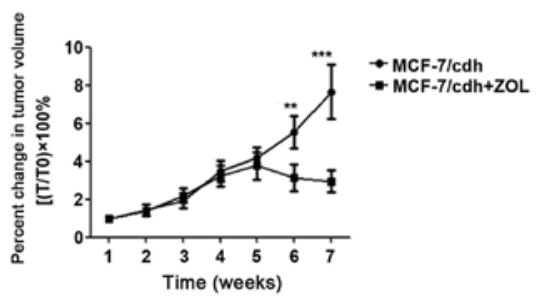

D

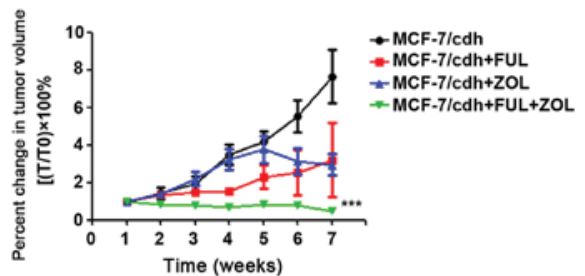

$\mathbf{E}$

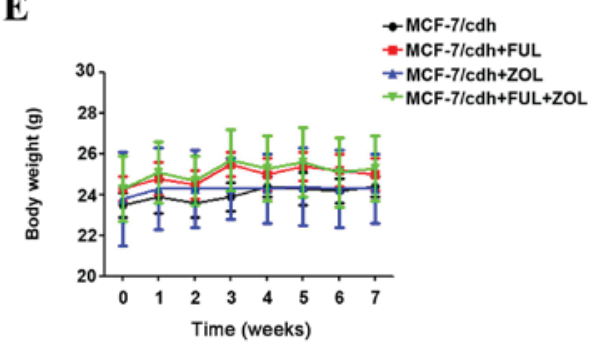

B
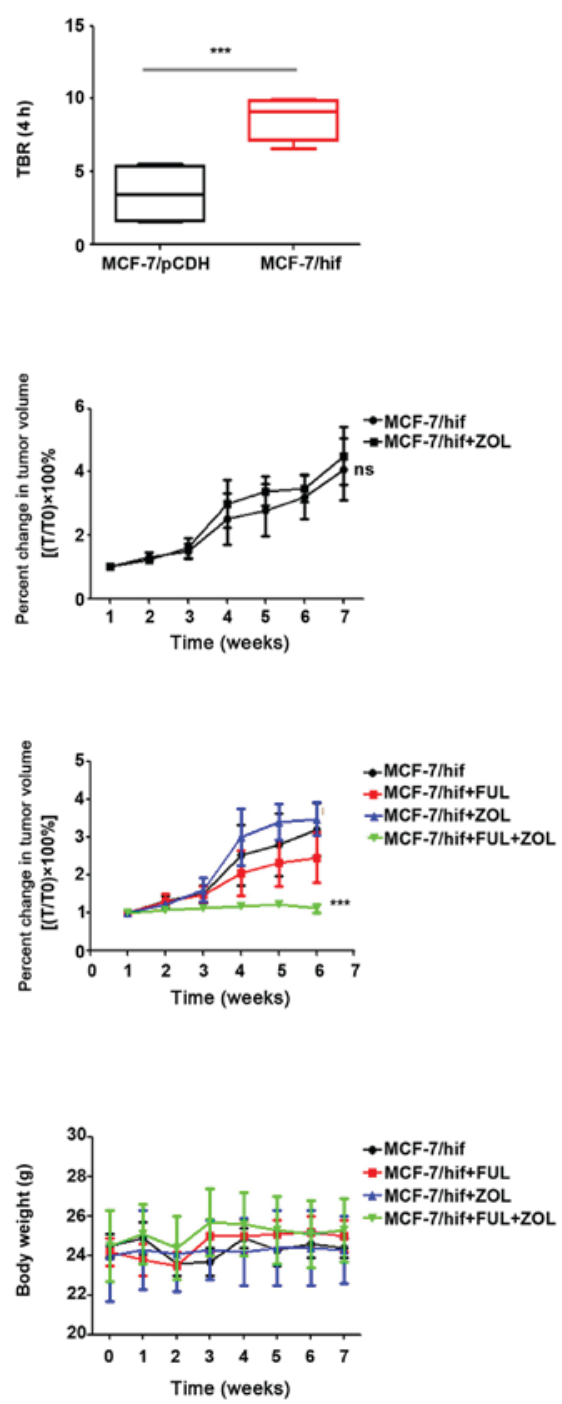

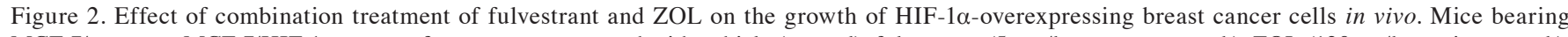
MCF-7/vector or MCF-7/HIF-1 $\alpha$ xenograft tumors were treated with vehicle (control), fulvestrant $(5 \mathrm{mg} / \mathrm{kg}$, once per week), ZOL (120 $\mu \mathrm{g} / \mathrm{kg}$, twice a week), or fulvestrant plus ZOL. (A) MCF-7/HIF-1 $\alpha$ cells grew faster and larger xenograft tumors compared with MCF-7/vector cells. (B) Analysis of xenografts tumors by $\left.{ }^{18} \mathrm{~F}\right]$-fluoromisonidazole static positron emission tomography-computer tomography. (C) The drug-sensitive MCF-7/vector xenograft tumor volumes were significantly reduced following ZOL treatment, while the growth of drug-resistant MCF-7/HIF-1 $\alpha$ tumors were not affected by ZOL treatment. (D) Combination of fulvestrant and ZOL significantly reduced the growth of MCF-7/vector and MCF-7/ HIF-1 $\alpha$ xenograft tumors. (E) Body weight of the animals in the experimental groups. ${ }^{* * *} \mathrm{P}<0.01$ and ${ }^{* * * *} \mathrm{P}<0.001$ vs. untreated control. ZOL, zoledronic acid; HIF, hypoxia-inducible factor; FUL, fulvestrant; TBR, tumor-to-background ratio.

expression was decreased following ZOL treatment, and this decrease was more evident in MCF-7/HIF-1 $\alpha$ cells under hypoxic conditions (Fig. 1B). MCF-7/HIF-1 $\alpha$ cells were then treated with fulvestrant alone, ZOL alone, or fulvestrant plus ZOL, and their effects on cell growth was determined in vitro. Either treatment alone did not show an inhibitory effect on the growth of MCF-7/HIF- $1 \alpha$ cells, suggesting that HIF- $1 \alpha$ overexpression renders these cells resistant to both treatments (Fig. 1C and D). The combination treatment of fulvestrant and ZOL, however, exerted a synergistic effect on MCF-7/HIF-1 $\alpha$ cells to strongly inhibit cell proliferation and growth $(\mathrm{P}<0.001$; Fig. 1D).

Combination treatment with fulvestrant and $\mathrm{ZOL}$ reduces the growth of HIF-1 $\alpha$-overexpressing breast cancer cells in vivo. To further investigate the effect of ZOL and fulvestrant combination treatment on breast cancer cell growth, an ER-positive breast cancer mouse model was established by using MCF-7-derived xenograft tumors. The ZOL dose $(120 \mu \mathrm{g} / \mathrm{kg})$ used in the present study is equivalent to the intravenous clinical dose of $4 \mathrm{mg}$ every 3 to 4 weeks. HIF-1 $\alpha$-overexpressing tumors grew faster and larger compared with control MCF-7 tumors $(\mathrm{P}<0.001$; Fig. $2 \mathrm{~A})$. The $\left[{ }^{18} \mathrm{~F}\right]-\mathrm{FMISO}$ uptake (TBR4 h) was significantly higher in HIF-1 $\alpha$-overexpressing xenograft tumors compared with control tumors $(\mathrm{P}<0.001$; Fig. 2B). Treatment with ZOL alone exerted no significant effect on the growth of HIF-1 $\alpha$-overexpressing tumors, although it significantly decreased the size of MCF-7/vector tumors $(\mathrm{P}<0.001$; Fig. 2C). However, the combination treatment of fulvestrant and ZOL significantly reduced the tumor volumes of both the control MCF-7/vector and the HIF-1 $\alpha$-overexpressing MCF-7/HIF-1 $\alpha$ xenograft tumors, compared with either single 
A

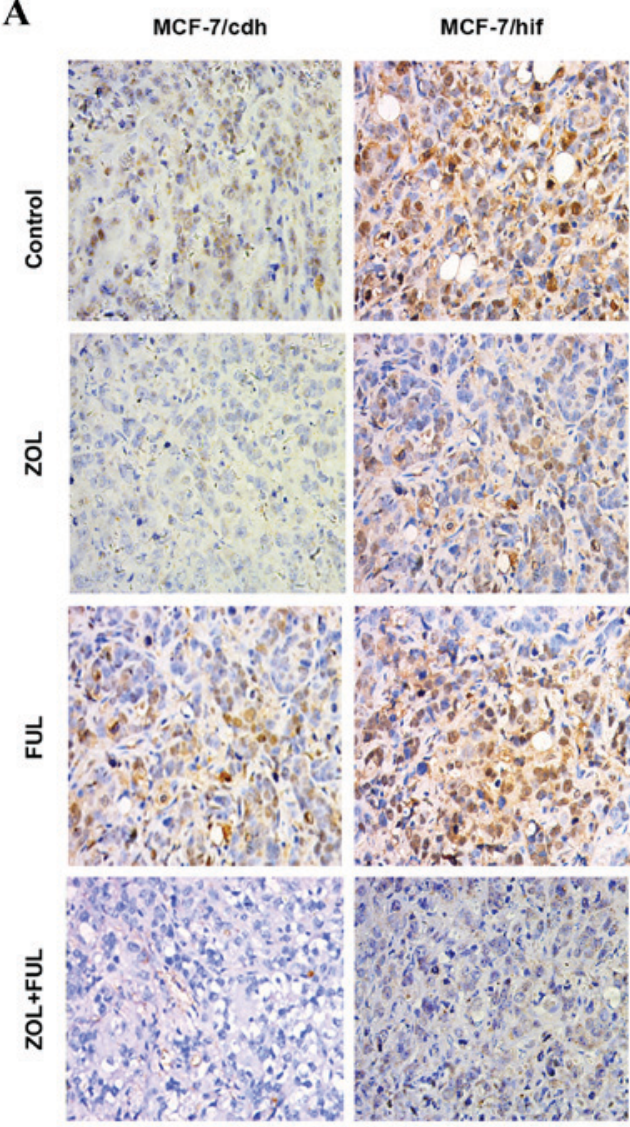

B

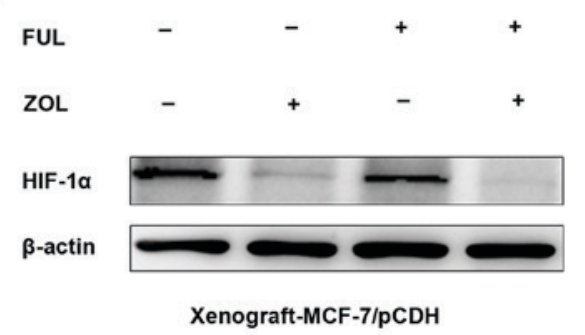

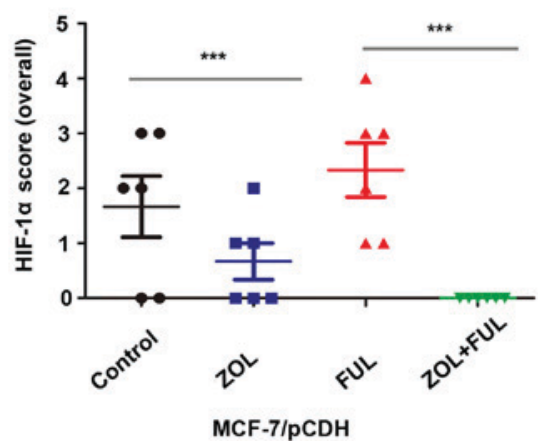
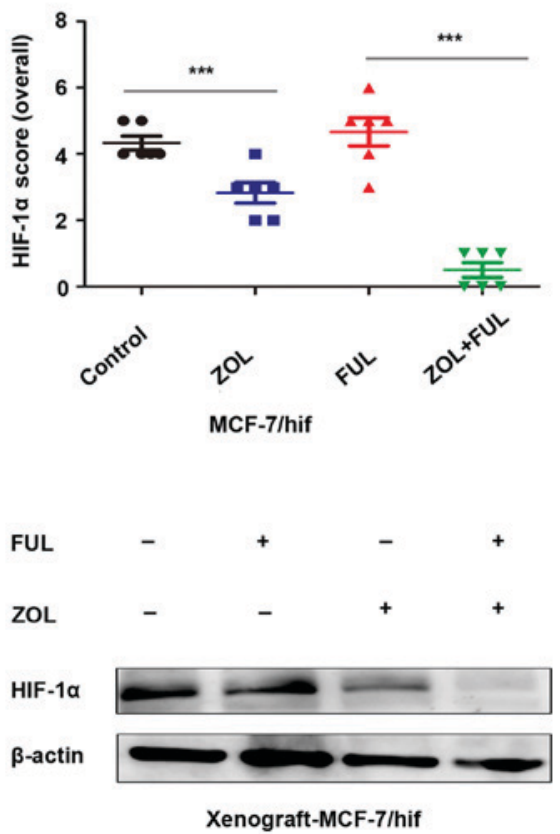

Figure 3. ZOL inhibits HIF-1 $\alpha$ expression in vivo. (A) Immunohistochemical analysis of HIF-1 $\alpha$ expression in xenograft tumor tissues from the four experimental groups. Representative images (magnification, x200) and quantification. (B) Representative images from western blot analysis of HIF-1 $\alpha$ expression in xenograft tumor tissues from the four experimental groups. ${ }^{* * *} \mathrm{P}<0.001$ vs. untreated control. ZOL, zoledronic acid; HIF, hypoxia-inducible factor; FUL, fulvestrant.

drug treatment $(\mathrm{P}<0.001 ;$ Fig. 2D). Of note, the drug treatments did not exert any side effects on animal body weight of either the MCF-7/vector and MCF-7/ HIF-1 $\alpha$ xenograft-bearing mice (Fig. 2E).

ZOL inhibits HIF-1 $\alpha$ expression in vitro and in vivo. A previous study has reported that ZOL inhibited HIF-1 $\alpha$ expression in vitro and in vivo (18). In the present study, HIF-1 $\alpha$ expression was demonstrated to be significantly decreased following $\mathrm{ZOL}$ treatment in vitro (Fig. 1B). In vivo, compared to untreated mice, IHC staining revealed that HIF-1 $\alpha$ expression was downregulated following ZOL treatment in both the MCF-7/vector and MCF-7/HIF-1 $\alpha$ xenograft tumors (Fig. 3A). No change was observed in either xenograft model following fulvestrant treatment (Fig. 3A). Combination of ZOL with fulvestrant had a synergistic effect in significantly further decreasing HIF-1 $\alpha$ expression in both the MCF-7/vector and MCF-7/HIF-1 $\alpha$ xenograft tumors (Fig. 3A). Western blotting analysis of the xenograft tumor tissues from the four experimental groups confirmed the IHC results for HIF- $1 \alpha$ protein expression (Fig. 3B).

ZOL inhibits HIF-1 $\alpha$ expression by blocking the ERK pathway. The present study demonstrated that HIF-1 $\alpha$ expression was inhibited by ZOL treatment in vitro (Fig. 4A) and in vivo (Fig. 3). However, the mechanisms remain unclear. PI3K/AKT and ERK1/2 signaling pathways are the main pathways involved in HIF-1 $\alpha$ activation (19). Therefore, the protein expression levels of key proteins associated with the $\mathrm{PI} 3 \mathrm{~K} / \mathrm{AKT}$ and ERK1/2 pathways were examined by western blotting in two ER-positive breast cancer cell lines, MCF-7 and T47D, treated with increasing concentrations of ZOL. The 
A
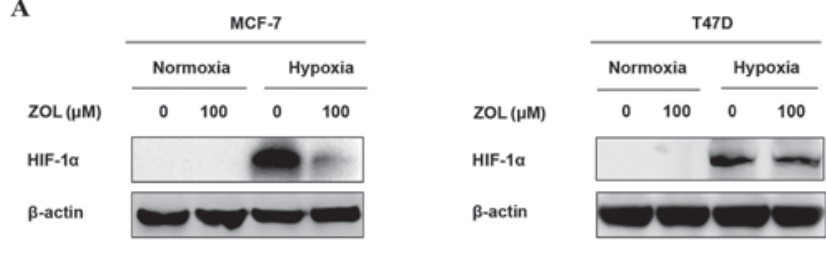

B

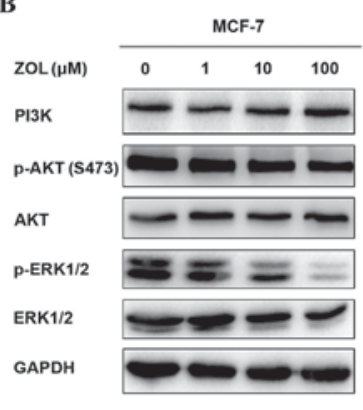

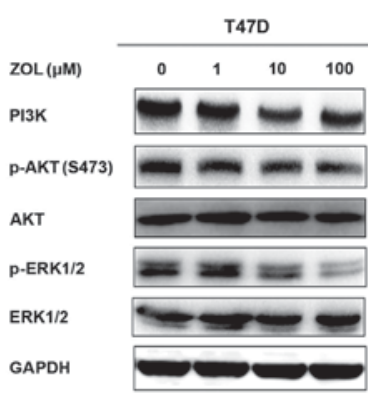

GAPDH

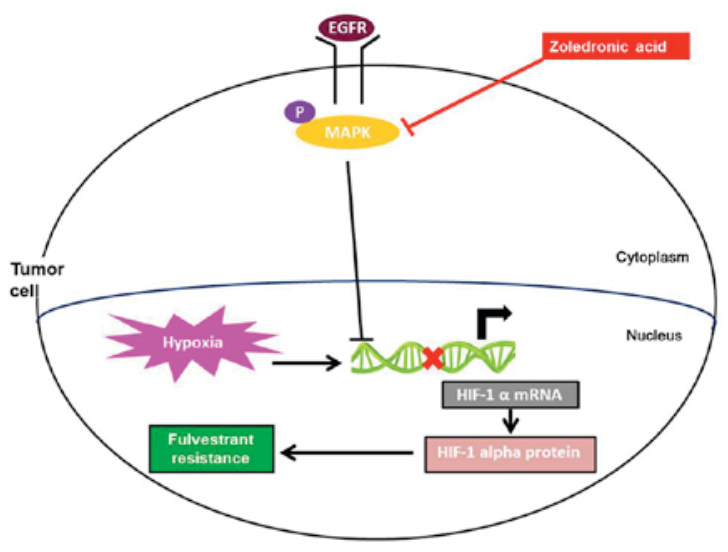

Figure 5. A schematic summarizing the role of the ERK/HIF-1 $\alpha$ pathway in reducing the sensitivity of ER-positive breast cancer cells to fulvestrant, and the synergy of zoledronic acid in suppressing ER-positive breast cancer growth. ERK, extracellular signal-regulated kinase; HIF, hypoxia-inducible factor; EGFR, epidermal growth factor receptor; MAPK, mitogen-activated protein kinase; p, phosphorylated.

studies from our group, $\left[{ }^{18} \mathrm{~F}\right]-$ FMISO PET/CT, a useful tool to detect hypoxia, was demonstrated to predict primary endocrine therapy resistance in breast cancer (17). HIF-1 $\alpha$ is an effective factor that adapts to hypoxia, and is associated with tumor initiation, progression and resistance to radiotherapy and chemotherapy (20-22). Mitochondrial metabolism dysregulation and tumor growth factor- $\beta /$ SMAD signaling promote breast cancer metastasis $(23,24)$, which may be associated with hypoxia to promote tumor progression and drug resistance.

In a previous study from our group, we reported that high HIF-1 $\alpha$ expression predicted resistance to endocrine therapy (18). ZOL, a standard drug for patients with bone metastasis and osteoporosis, increased the sensitivity to antiestrogen treatment through HIF-1 $\alpha$ inhibition in ER-positive breast cancer (18). In the present study, we demonstrated that combination treatment of fulvestrant and ZOL significantly inhibited the growth of HIF-1 $\alpha$-overexpressing MCF-7 cells in vitro and in a xenograft model, while single fulvestrant treatment did not inhibit the growth of HIF-1 $\alpha$-overexpressing MCF-7 cells. These results indicated that HIF- $\alpha$ may reduce the sensitivity of breast cancer cells to fulvestrant, but ZOL treatment restored the sensitivity to fulvestrant in vitro and in vivo.

$\mathrm{ZOL}$ is a nitrogen-containing bisphosphonate, which attaches to the mineralized bone matrix, inhibits bone resorption and prevents the occurrence of skeletal-related events (9). Increasing evidence has indicated that ZOL exerts antitumor activity in vitro and in vivo (25-27). Various in vivo studies have investigated the therapeutic value of $\mathrm{ZOL}$ alone or in combination with conventional chemotherapy and mechanistic target of rapamycin (mTOR) inhibitors on the growth of tumors (28-30). In the present study, the mechanism by which ZOL restored sensitivity to fulvestrant was examined. ZOL significantly inhibited ERK1/2 phosphorylation in breast cancer cells, while the PI3K/AKT signaling pathway was not affected. Addition of EGF, an ERK activator, reversed the inhibition of ERK1/2 activation and HIF-1 $\alpha$ expression following ZOL treatment. These results demonstrated that ZOL inhibited

HIF-1 $\alpha$ expression by blocking the ERK pathway.
ER-positive breast cancer accounts for $70-80 \%$ of all breast cancers, for which endocrine therapy is the standard treatment. However, $30-40 \%$ of patients relapse following endocrine therapy, which indicates drug resistance (4). In previous 
In conclusion, the present study suggests that inhibition of ERK/HIF-1 $\alpha$ by ZOL may increase the sensitivity of ER-positive breast cancer cells to fulvestrant. The combination of ZOL and fulvestrant may serve as a new therapeutic scheme for patients with recurrent ER-positive breast cancer.

\section{Acknowledgements}

The present study was supported by the National Natural Science Foundation of China (grant no. NSFC81301246).

\section{References}

1. Siegel RL, Miller KD and Jemal A: Cancer statistics, 2016. CA Cancer J Clin 66: 7-30, 2016.

2. Fan L, Strasser-Weippl K, Li JJ, St Louis J, Finkelstein DM, Yu KD, Chen WQ, Shao ZM and Goss PE: Breast cancer in China. Lancet Oncol 15: e279-e289, 2014.

3. Chen W, Zheng R, Baade PD, Zhang S, Zeng H, Bray F, Jemal A, Yu XQ and He J: Cancer statistics in China, 2015. CA Cancer J Clin 66: 115-132, 2016.

4. Jia X, Liu G, Cheng J, Shen Z and Shao Z: CYR61 contributes to poor response to letrozole in ER positive breast carcinoma. Curr Cancer Drug Targets, 2016.

5. Masood S: Estrogen and progesterone receptors in cytology: A comprehensive review. Diagn Cytopathol 8: 475-491, 1992.

6. Bross PF, Baird A, Chen G, Jee JM, Lostritto RT, Morse DE, Rosario LA, Williams GM, Yang P, Rahman A, et al: Fulvestrant in postmenopausal women with advanced breast cancer. Clin Cancer Res 9: 4309-4317, 2003.

7. Ciruelos E, Pascual T, Arroyo Vozmediano ML, Blanco M, Manso L, Parrilla L, Muñoz C, Vega E, Calderón MJ, Sancho B and Cortes-Funes $\mathrm{H}$ : The therapeutic role of fulvestrant in the management of patients with hormone receptor-positive breast cancer. Breast 23: 201-208, 2014

8. Polascik TJ and Mouraviev V: Zoledronic acid in the management of metastatic bone disease. Ther Clin Risk Manag 4 261-268, 2008

9. Russell RG: Bisphosphonates: Mode of action and pharmacology. Pediatrics 119 (Suppl 2): S150-S162, 2007.

10. Mundy GR: Metastasis to bone: Causes, consequences and therapeutic opportunities. Nat Rev Cancer 2: 584-593, 2002.

11. Fromigue O, Lagneaux L and Body JJ: Bisphosphonates induce breast cancer cell death in vitro. J Bone Miner Res 15: 2211-2221, 2000.

12. Jagdev SP, Coleman RE, Shipman CM, Rostami-HA and Croucher PI: The bisphosphonate, zoledronic acid, induces apoptosis of breast cancer cells: Evidence for synergy with paclitaxel. Br J Cancer 84: 1126-1134, 2001.

13. Virtanen SS, Väänänen HK, Härkönen PL and Lakkakorpi PT: Alendronate inhibits invasion of PC-3 prostate cancer cells by affecting the mevalonate pathway. Cancer Res 62: 2708-2714, 2002.

14. Boissier S, Ferreras M, Peyruchaud O, Magnetto S, Ebetino FH, Colombel M, Delmas P, Delaissé JM and Clézardin P: Bisphosphonates inhibit breast and prostate carcinoma cell invasion, an early event in the formation of bone metastases. Cancer Res 60: 2949-2954, 2000.

15. Fournier P, Boissier S, Filleur S, Guglielmi J, Cabon F, Colombel M and Clézardin P: Bisphosphonates inhibit angiogenesis in vitro and testosterone-stimulated vascular regrowth in the ventral prostate in castrated rats. Cancer Res 62, 6538-6544, 2002.
16. Wood J, Bonjean K, Ruetz S, Bellahcène A, Devy L, Foidart JM, Castronovo V and Green JR: Novel antiangiogenic effects of the bisphosphonate compound zoledronic acid. J Pharmacol Exp Ther 302: 1055-1061, 2002.

17. Cheng J, Lei L, Xu J, Sun Y, Zhang Y, Wang X, Pan L, Shao Z, Zhang Y and Liu G: 18F-fluoromisonidazole PET/CT: A potential tool for predicting primary endocrine therapy resistance in breast cancer. J Nucl Med 54: 333-340, 2013.

18. Jia X, Hong Q, Lei L, Li D, Li J, Mo M, Wang Y, Shao Z, Shen Z, Cheng J and Liu G: Basal and therapy-driven hypoxia-inducible factor-1alpha confers resistance to endocrine therapy in estrogen receptor-positive breast cancer. Oncotarget 6: 8648-8662, 2015.

19. Yang XM, Wang YS, Zhang J, Li Y, Xu JF, Zhu J, Zhao W, Chu DK and Wiedemann P: Role of PI3K/Akt and MEK/ERK in mediating hypoxia-induced expression of HIF-1alpha and VEGF in laser-induced rat choroidal neovascularization. Invest Ophthalmol Vis Sci 50: 1873-1879, 2009.

20. Aebersold DM,Burri P, Beer KT,Laissue J,Djonov V, Greiner RH and Semenza GL: Expression of hypoxia-inducible factor-1alpha: A novel predictive and prognostic parameter in the radiotherapy of oropharyngeal cancer. Cancer Res 61: 2911-2916, 2001.

21. Zhong H, De Marzo AM, Laughner E, Lim M, Hilton DA, Zagzag D, Buechler P, Isaacs WB, Semenza GL and Simons JW: Overexpression of hypoxia-inducible factor 1alpha in common human cancers and their metastases. Cancer Res 59: 5830-5835, 1999.

22. Bachtiary B, Schindl M, Pötter R, Dreier B, Knocke TH, Hainfellner JA, Horvat R and Birner P: Overexpression of hypoxia-inducible factor 1alpha indicates diminished response to radiotherapy and unfavorable prognosis in patients receiving radical radiotherapy for cervical cancer. Clin Cancer Res 9: 2234-2240, 2003.

23. Jiang HL, Sun HF, Gao SP, Li LD, Huang S, Hu X, Liu S, Wu J, Shao ZM and Jin W: SSBP1 suppresses TGF $\beta$-driven epithelial-to-mesenchymal transition and metastasis in triple-negative breast cancer by regulating mitochondrial retrograde signaling. Cancer Res 76: 952-964, 2016.

24. Jiang HL, Sun HF, Gao SP, Li LD, Hu X, Wu J and Jin W: Loss of RAB1B promotes triple-negative breast cancer metastasis by activating TGF- $\beta /$ SMAD signaling. Oncotarget 6: 16352-16365, 2015.

25. Senaratne SG, Pirianov G, Mansi JL, Arnett TR and Colston KW: Bisphosphonates induce apoptosis in human breast cancer cell lines. Br J Cancer 82: 1459-1468, 2000.

26. Gnant $\mathrm{M}$ and Clézardin P: Direct and indirect anticancer activity of bisphosphonates: A brief review of published literature. Cancer Treat Rev 38: 407-415, 2012.

27. Clézardin P, Fournier P, Boissier S and Peyruchaud O: In vitro and in vivo antitumor effects of bisphosphonates. Curr Med Chem 10: 173-180, 2003.

28. Ottewell PD, Mönkkönen H, Jones M, Lefley DV, Coleman RE and Holen I: Antitumor effects of doxorubicin followed by zoledronic acid in a mouse model of breast cancer. J Natl Cancer Inst 100: 1167-1178, 2008.

29. Heymann D, Ory B, Blanchard F, Heymann MF, Coipeau P, Charrier C, Couillaud S, Thiery JP, Gouin F and Redini F: Enhanced tumor regression and tissue repair when zoledronic acid is combined with ifosfamide in rat osteosarcoma. Bone 37: 74-86, 2005.

30. Moriceau G, Ory B, Mitrofan L, Riganti C, Blanchard F, Brion R, Charrier C, Battaglia S, Pilet P, Denis MG, et al: Zoledronic acid potentiates mTOR inhibition and abolishes the resistance of osteosarcoma cells to RAD001 (Everolimus): Pivotal role of the prenylation process. Cancer Res 70: 10329-10339, 2010. 